\title{
Antecedents and Consequences of School Belonging: Empirical Evidence and Implications for Practices
}

\author{
Huy P. Phan ${ }^{1}$ \\ ${ }^{1}$ School of Education, The University of New England, Armidale, Australia \\ Correspondence: Huy P. Phan, School of Education, The University of New England, Armidale NSW, 2351, \\ Australia. Tel: 61-2-6773-3327. E-mail: hphan2@une.edu.au
}

Received: May 20, 2013

doi:10.5539/jedp.v3n2p117

\author{
Accepted: June 3, 2013 \\ Online Published: September 24, 2013 \\ URL: http://dx.doi.org/10.5539/jedp.v3n2p117
}

\begin{abstract}
There are number of theoretical orientations, which may account and explain students' learning and performance outcomes in various domains of functioning. Triarchic relations between three major theoretical orientations were proposed and explored in this study. In their sequencing of predictive effects, these included: personal self-efficacy, school belonging, and academic disengagement. The proposition, in this case, stipulated both personal self-efficacy and academic disengagement as antecedent and consequence of belonging, respectively. These three variables are also conceptualized, centrally, between prior learning experience and future performance in mathematics. Two hundred and ninety $12^{\text {th }}$ grade students (152 boys and 138 girls) participated in this study. Self-rating responses of Likert-scale inventories (e.g., MSLQ) were analysed using structural equation modelling procedures. Structural analyses yielded some significant evidence, notably the impact of both personal self-efficacy beliefs and a sense of belonging on academic performance in mathematics. A positive sense of belonging to school also relates inversely to academic disengagement. Finally, consistent with Bandura's $(1986,1997)$ social cognitive theory, personal self-efficacy is central to the relation between enactive learning experience and academic performance.
\end{abstract}

Keyword: academic disengagement, belonging, enactive learning experience, personal self-efficacy

\section{Introduction}

Quality learning has a myriad of educational implications, one of which involves a contemplation of positive futures for students (e.g., a career choice). There are a number of psychological theories that encourage and enhance quality learning and positive experiences for educators and students, alike. The importance of school belonging, in particular, has been recognized as a non-cognitive psychological construct that makes a major contribution (Anderman, 2002; Capps, 2003; Goodenow \& Grady, 1993; Willms, 2003). This theoretical orientation originates, in part, from the work of Abraham Maslow (1962), which emphasizes a need for us, as individuals, to feel belonged to a society or a community. In the contexts of academic learning, there is substantial research that has explored the importance of students' well-being and positioning within a school social milieu. Students' sense of belonging to a school has consequences that transcend beyond classroom learning. Positive feelings of belonging may, for example, may strengthen one's own motivation to succeed in life and to have proactive social relationships with others (Ma, 2003).

From an educational perspective, in terms of applied instructional practices, there is an impetus for educators to consider strategies and/or pathways that consequently result in positive perceptions and experiences of belonging. Previous empirical studies suggest there are facets that could serve as both antecedents and consequences of belonging. Notably, from our examination of the literature, two major constructs that could reflect both adaptive and maladaptive practices, respectively, include: personal self-efficacy (Bandura, 1977, 1997) and academic disengagement (Martin \& Marsh, 2005; Willms, 2003; Wolters, 2003). In the present study, within the framework of structural equation modelling (SEM)(Bandura, 1997; Byrne, 1998; Kline, 2011; Loehlin, 2004), we explored the impact of belongingness on academic disengagement and academic achievement, with personal self-efficacy acting as a possible antecedent. We used a variety of Likert-scale inventories and administered these to a cohort of upper secondary school students $(N=290)$. 


\subsection{Theoretical Overview: The Importance of Belonging}

The notion of belonging is rather complex and scopes a number of important attributes for consideration and implementation. Goodenow and Grady's (1993) definition of belonging is well recognized by scholars, and entail the extent to which students "feel personally accepted, respected, included, and supported in the school environment" (Ma, 2003, p. 1). This theoretical orientation in the field of educational psychology is significant, and has attracted and renewed interests from both the public and educators, alike (Anderman, 2002; Ma, 2003). The fostering of school belonging, for instance, may have wider achievement-related and social implications other than just classroom learning, alone.

A sense of belonging is grounded in a number of theoretical perspectives and views, such an inner desire to establish affection between people (Murray, 1938), a need for us to seek positive regards from others (Rogers, 1951), a need for relatedness (Deci \& Ryan, 1991; Ryan, 1993; Vallerand, 1997), or simply a reflection of Maslow's (1962) humanistic theory of motivation on an inner need for satisfaction and gratification. What is common, though, is that there is connection to one's emotions, well-being, and self-esteem within the social milieu, at large. An amalgamation of key words to represent and denote a sense of belonging includes, for example: relatedness, community, inner needs, identification, identity, caring, protection, bonding, peer relationship, social contact, and collectivism. Baumeister and Leary's (1995) proposition, titled 'belongingness hypothesis', reflecting Maslow's (1962) own tenets sums up the importance of human nature for love and belonging - "... human beings have a pervasive drive to form and maintain at least a minimum quantity of lasting, positive, and significant interpersonal relationships" (Baumeister \& Leary, 1995, p. 497). Finn's (1989) participation-identification model is rather unique, and emphasizes a need for students to identify with their schools in order to develop a perception of school belonging (e.g., feel welcomed, valued).

The importance of belonging, reflecting the mentioned attributes, has a number of implications for continuing research development. There is a plethora of research studies that emphasize the significance of students' sense of belonging and/or the absence thereof (Capps, 2003; Willms, 2003). Fostering a positive sense of belonging for students is essential to their educational processes and schooling outcomes (Ma, 2003). Maladaptively, for example, students' perceived lack of school belonging may result in dropout (Anderman, 2002; Fine, 1991; Finn, 1989) and other related negative behaviours, such as participation in antisocial activities and violence (Ma, 2003). Peer rejection, often experienced by some students at school, is likely to weaken learning interest, leading ultimately to dropout and delinquency.

Belonging, in contrast, leads to positive consequences for students, both academic and non-academic (Anderman, 2002; Deci \& Ryan, 1991; Finn, 1989; Osterman, 2000; Willms, 2003). In particular, as the research has shown, the fostering of a school social milieu that encourages some of the mentioned attributes (e.g., embracing students with positive values) is likely to enhance effort expenditure, motivation, and learning (Gonzalez \& Padilla, 1997; Goodenow, 1993a; Goodenow \& Grady, 1993; Osterman, 2000; Voelkl, 1997). An environment that enhances social support and positive peer relationships, for instance, promotes students' school engagement (Becker \& Luthar, 2002; Garcia-Reid, Reid, \& Peterson, 2005; Goodenow, 1992).

\subsubsection{Antecedents of Belonging}

In educational settings, we need to consider the various antecedents that could nurture and encourage a positive sense of belonging. Existing empirical evidence suggests there are a number of theoretical orientations, which may serve to influence and enhance students' sense of belonging. Positively, in line with social cognitive theory (Bandura, 1986, 2002), the tenet of personal self-efficacy, defined as "beliefs in one's capabilities to organize and execute the courses of action required to produce given attainments" (Bandura, 1997, p. 3), is an important self-evaluation process that influences individuals' behaviours - for example, the choice that one makes in life (e.g., an individual opting to study a vocational course). Self-efficacy assists individuals in their mobilization of effort on a learning activity, resilience in the face of adverse situations, and persistence when confronting obstacles. Furthermore, according to Bandura (1997), self-efficacy influences individuals' thought patterns and emotional reactions - for example, a weakened sense of self-efficacy entails a perception that things are tougher than they really are, leading to stress, depression, and a restricted view as to how one would solve a problem (Pajares, 1996b). A heightened sense of self-efficacy, in contrast, creates the feeling of serenity when one approaches difficult tasks and activities.

Personal self-efficacy then, according to Bandura $(1977,1997)$, features as an important psychological construct in human agency. There is a voluminous body of research in the empirical literature, attesting to the potency of personal self-efficacy as a direct and indirect contributor of individuals' learning and performances in achievement contexts (Pajares, 1996b; Schunk, 1995; William \& Williams, 2010). Quantitatively, for example, 
the use of multivariate and structural equation analyses by a number of researchers has yielded clear and consistent evidence, indicating the positive effects of self-efficacy beliefs on quality learning and other achievement-related outcomes (e.g., study processing strategies)(e.g., Diseth, 2011; Fast, et al., 2010; Liem, Lau, \& Nie, 2008; Pajares \& Miller, 1994; Phan, 2010; Prat-Sala \& Redford, 2010; William \& Williams, 2010). The established efficacy-achievement relationship, in this analysis, provides a premise for us to consider whether students' self-judgments of capabilities (e.g., "I feel confident that I have capability to succeed in my schoolwork") could, similarly, influence their sense of belonging. A heightened state of academic self-efficacy, for instance, may instil confidence and self-esteem, thereby resulting in positive learning experiences at school (e.g., connectedness). Self-efficacious students, in this analysis, may feel more inclined to identify with their peers and social surroundings. Self-efficacy, according to Bandura (1997), mobilizes effort and persistence and, in this case, enables students to have positive outlooks towards others.

Consistent with Bandura's $(1986,1997)$ theoretical tents, we contend that enactive learning experiences may also serve to predict and explain students' sense of belonging. The works of Bandura (1997) and other scholars, for example, suggest that students rely predominantly on enactive performance accomplishments (e.g., repeated successes in mathematics) to formulate their self-efficacy beliefs (e.g., Britner \& Pajares, 2006; Hampton, 1998; Lent, Lopez, \& Bieschke, 1991; Liem, et al., 2008; Lopez \& Lent, 1992; Pajares, Johnson, \& Usher, 2007; Phan, 2012a). Positive learning experiences subject to mastery criteria, in particular, may co-exist with personal self-efficacy to influence students' sense of belonging. Enriched learning experiences may instil a sense of personal accomplishments, enabling students to appreciate schooling and view school, in general, as a favourable portal for development and academic excellence. Continuing failures to learn and master schoolwork, in contrast, may alienate some students from their peers and school. Bloom's (1976) own assertion in this matter suggests that incompetency may cause emotional difficulties and feelings of alienation from school for some students.

\subsubsection{Consequences of Belonging}

We also identify, in contrast, the maladaptive practice of academic disengagement, as a detrimental consequence of belonging. Disengagement or the term "disengaged from school", according to Willms (2003), reflects characteristics of those students "who do not feel they belong at school and have withdrawn from school activities in a significant way" (Willms, 2003, p. 8). Disengagement contrasts with academic engagement, where the latter construct emphasizes the importance of identity, positive school values, and students participating in school activities. Disengagement, similar to the work of personal self-efficacy (Bandura, 1986, 1997), has been researched in educational and motivational contexts (Fredricks, Blumenfeld, \& Paris, 2004; Greene \& Miller, 1996; Greenwood, Horton, \& Utley, 2002; Martin \& Marsh, 2005; Willms, 2003).This area of inquiry is of significance, especially when we consider the educational implications that arise from students' engagement and disengagement. Some studies have found, for example, that academic disengagement is related closely to negative consequences, such as early student dropout, juvenile delinquency, and problem substance use (e.g., Henry, 2010; Henry, Knight, \& Thornberry, 2012; Moretti, 2005; Rouse, 2005). The inequalities in achievements of minority ethnic students (Henry, et al., 2012; Woolf, Johnson, Phillips, \& Philipsen, 2007), likewise, may be explained and accounted for by the feeling and experience of alienation. Some students may opt to adopt a criminal lifestyle, forging antisocial identity as a defence for their shortcomings and isolation.

Belonging then, as a theoretical construct, may be a prominent precursor to academic engagement. There is evidence to suggest that a sense of belonging relates closely to academic motivation, engagement, and performance, especially for those students from ethnic backgrounds and/or less advantaged families (Connell \& Wellborn, 1991; Goodenow, 1993a; Osterman, 2000). Students who perceive a sense of belonging in educational environments are likely, in this analysis, to feel motivated and engaged in classroom learning and schoolwork (Osterman, 2000). A positive sense of belonging, in this case, enables students to experience enthusiasm, happiness, enjoyment, interest, and strengthened confidence in their learning (Furrer \& Skinner, 2003). For minority students, in particular, the fostering of a social milieu that embraces belonging is appreciative, as this sense of connectedness, support and respect for personal autonomy (Goodenow, 1993a) relates to academic motivation and classroom engagement (Becker \& Luthar, 2002). A lack of belonging, in contrast, may lead to a number of detrimental consequences, such as a lack in dedication and motivation. Students who perceive and experience a lack of belonging at school may, consequently, isolate themselves and withdraw from peers and school activities.

\subsection{A Conceptual Framework for Examination}

The study of quality learning and appreciation for schooling is an important feat for educators and researchers to consider. One central theme for emphasis, in this analysis, entails an examination of both antecedents and 
consequences of belonging. The focus of this investigation, drawn from previous empirical evidence, is significant for its amalgamation of two major inquiries: (1) the role of personal self-efficacy (Bandura, 1977, 1997) as an antecedent of belonging and academic disengagement, and (2) the predictive effects of belonging and academic disengagement on performance. Figure 1 depicts our conceptualization and illustrates, in particular, the following hypotheses:

Hypothesis 1: It is hypothesized that personal self-efficacy would exert positive effects on belonging and academic achievement, and a negative effect on academic disengagement.

Hypothesis 2: It is hypothesized that a sense of belonging would exert a positive effect on academic achievement, and a negative effect on disengagement.

Hypothesis 3: It is hypothesized that disengagement would exert a negative effect on academic achievement.

Hypothesis 4: It is hypothesized that prior learning experiences would exert positive effects on personal self-efficacy, a sense of belonging and academic achievement, and a negative effect on disengagement.

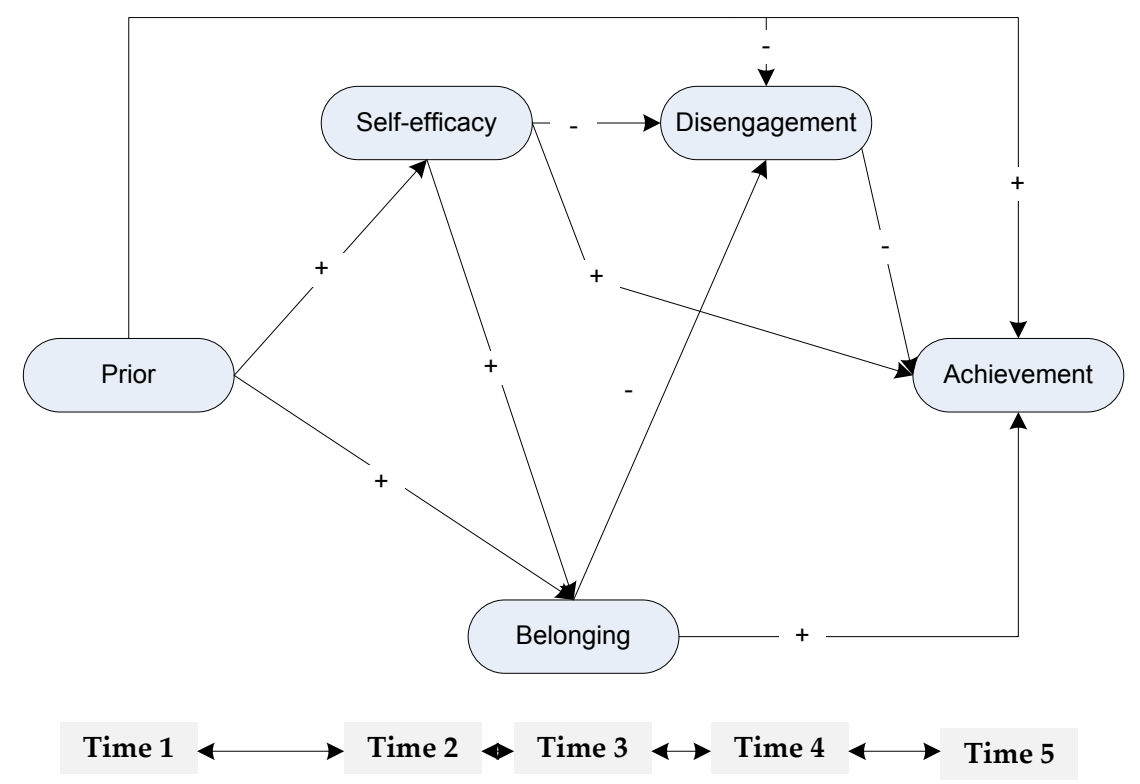

Figure 1. A conceptual model for investigation

Note. '+' and '-' denote positive and negative relations, respectively. For example, prior learning experience is hypothesized to exert a positive effect on personal self-efficacy.

The depiction, as illustrated from the four mentioned hypotheses, conceptualizes the triarchic relations between personal self-efficacy, belonging, and academic disengagement. Evidence ascertained from this investigation may clarify the positioning of antecedents and consequences of belonging. Does self-efficacy influence academic disengagement indirectly, via belonging? Does belonging influence performance indirectly, via academic disengagement? More importantly, decomposing both the direct and indirect effects, we may be able to discern and trace trajectories from prior learning experience to achievement outcome, via personal self-efficacy, belonging, and academic disengagement. Validation of these structural relations may provide fruitful information for teachers and educational practitioners in their considerations towards the promotion of positive and adaptive outcomes.

\section{Methods}

\subsection{Sample}

Three hundred and nine $12^{\text {th }}$ grade students took part in this study, which was funded and approved by our university. The data, from three government schools in Sydney, was collected from late 2012 to early April, 2013. Given the final year of secondary schooling in Australia is crucial, logistically, we had very limited, if any, opportunities to stipulate a particular time in data collection. We collected and administered the questionnaire on 
five separate occasions: (i) Time 1 in Early-December, 2012, with the collection of students' $11^{\text {th }}$ grade results in mathematics, (ii) Time 2 in the first week of February, 2013, with the administration of the personal self-efficacy questionnaire, (iii) Time 3 in the last week of February, 2013, with the administration of the belonging questionnaire, (iv) Time 4 in Mid-March, 2013, with the administration of the academic disengagement questionnaire, and (v) the collection of end-of-term results in Early-April, 2013. This short-term longitudinal examination, with multiple time points in data collection, is advantageous, theoretically, and may provide fruitful information into the temporally displaced influences of psychological variables. There has been precedence, more recently, for researchers to explore and study cognitive and motivational variables in educational settings within a longitudinal framework (Bong, 2001; Phan, 2011; Wong \& Watkins, 1998). Due to missing data, a final sample of 290 (152 boys and 138 girls) was included in the subsequent statistical analyses.

We administered three Likert-scale inventories, as explained below, in classes with the assistance of a doctoral student. University protocols, including ethical procedures were explained and followed. For example, apart from the notion of anonymity, we also explained to the students that their participation was voluntary and why there their results for mathematics were needed.

\subsection{Instruments}

One subject discipline that is important is mathematics, and many secondary school students in Australia undertake this subject with a view to use it as a pre-requisite for university entry into various undergraduate courses. Consequently, where appropriate, we asked the participants to situate their considerations and responses within the contexts of mathematics learning.

\subsubsection{Academic Self-Efficacy}

We used the self-efficacy scale of the Motivated Strategies for Learning Questionnaire (MSLQ)(Pintrich, Smith, Garcia, \& McKeachie, 1991) to measure students' academic self-efficacy beliefs. The eight items, self-rating on a 7-point rating scale (1 (Not at all true of me) to 7 (Very true of me)), were modified slightly to fit in with the contexts of mathematics learning (Pajares, 1996b). The modified items included, for example: "I'm certain I can understand the most difficult material presented in the readings for this subject, mathematics" and "I'm confident I can understand the most complex material presented by the teacher in this subject, mathematics".

\subsubsection{Belonging}

We used the Psychological Sense of School Membership (PSSM) Scale (Goodenow, 1993b) to measure students' sense of belonging. The PSSM has 18 items, which we asked students to rate on a 7-point rating scale: 1 (Not at all true) to 7 (Completely true). Five of the items were worded in a negative valence approach (e.g., "Sometimes I feel as if I don't belong here"), and 13 positive (e.g., "I feel like a real part of (name of school)"). For the subsequent statistical analyses, however, we reversed the scores of the negatively-worded items to align to the 13 positive valenced items.

\subsubsection{Academic Disengagement}

We used two items of Martin and Marsh's (2005) research (e.g., "I often feel like giving up in this subject, mathematics") and adapted nine items from Artino and Stephens' (2009) version of Wolters' (2004) (e.g., "I often find excuses for not starting the work for this mathematics class") research to measure students' academic disengagement. Of the 11 items, which were rated on a 7-point Likert scale (1 (Completely disagree) to 7 (Completely agree), two items were worded positively (e.g., "I look forward to learning more about this subject, mathematics, in the future") and nine negatively (e.g., "I often find excuses for not starting the work for this mathematics class").

\subsubsection{Academic Achievement in Mathematics Learning}

Similar to previous research studies, we used the students' end-of-term results for mathematics as an index of achievement in mathematics learning. This end-of-term result for each student constitutes two components: (i) Course mark that is made up of periodic quizzes and assessment tasks, and (ii) End-of-term examination.

\subsubsection{Prior Learning Experience}

We used students' previous $11^{\text {th }}$ grade yearly results for mathematics as an index of prior mathematics achievement. This methodological approach, used in a number of studies in personal self-efficacy and motivational beliefs (e.g., Liem, et al., 2008; Phan, 2012a), differs from students' self-reporting of their previous learning and achievements via Likert-scale questionnaires (e.g., "I got a high grade in last year's math class": Lent, et al., 1991). This measure of student self-reporting, commonly acknowledged and used in previous research (Hampton, 1998; Lent, et al., 1991; Usher \& Pajares, 2009), has been reasoned to provide inaccurate 
information about one's own judgments and reflections of mastery experiences - for example, noting down the receiving of good academic grades when, in fact, this is not true.

\section{Results}

For this research investigation, we used structural equation modelling (SEM) procedures (Byrne, 1998; Kline, 2011; Loehlin, 2004) to test and validate the hypothesized relations that were mentioned in the preceding sections. This statistical technique, in contrast to other multivariate approaches for its emphasis on both latent factors and measured indicators, has been used in previous research to explore the relations between personal self-efficacy and other related motivational-related variables (e.g., Fenollar, Román, \& Cuestas, 2007; Liem, et al., 2008; Phan, 2010; Sins, van Joolingen, Savelsbergh, \& van Hout-Wolters, 2008). SEM is more advantageous at it assumes that measured indicators have errors (i.e., $\mathrm{E} \neq 0$ ), and that we can assess and evaluate both measurement and structural relationships simultaneously. Furthermore, with the availability of modification fit index (MI) and goodness-of-fit index values, SEM allows researchers to propose and test competing a priori models for acceptance. In relation to the latter, there are a number of goodness-of-fit index values available, but for this investigation, similar to previous studies, we chose to use the following: the chi-square statistics $\left(\chi^{2}\right)$ and degree of freedom $(\mathrm{d} f)$, Comparative Fit Index (CFI)(CFI $\geq .90)$, the Non-normed Fit Index (NNFI)(NNFI $\geq .90)$, and the Root Mean Square Error of Approximation (RMSEA)(RMSEA $\leq .80$ ).

The statistical software packages SPSS21 and SPSS AMOS 20 were used to assist in the descriptive and latent variables analyses. Following the protocols that have been established previously (Byrne, 2010; Kline, 2011; Schumacker \& Lomax, 2004), we used covariance matrices and maximum likelihood solutions. Correlational matrix analysis, for example, has been known to entail potential problems, such as producing incorrect goodness-of-fit index values and standard errors (Byrne, 1998; Jöreskog \& Sörbom, 2001). Maximum likelihood procedure, similarly, has been noted to perform reasonably well when data are normally distributed (Chou \& Bentler, 1995). The descriptive statistics, involving the means and standard deviations for the total sample and individual groups (boys versus girls) are presented in Table 1.

Table 1. Descriptive statistics of means and standard deviations

\begin{tabular}{llll}
\hline Instruments & Means & & $\begin{array}{l}\text { Means } \\
\text { Total sample }\end{array}$ \\
\hline Beys & Girls & $5.38(1.23)$ & $5.30(1.36)$ \\
Belonging & $5.22(1.47)$ & $5.91(.76)$ & $5.90(.76)$ \\
Academic disengagement & $5.89(.77)$ & $2.15(.81)$ & $2.16(.82)$ \\
Academic achievement & $2.16(.83)$ & $52.00(4.98)$ & $52.06(5.06)$ \\
Prior achievement & $52.12(5.14)$ & $55.36(7.12)$ & $54.04(7.60)$ \\
\hline
\end{tabular}

Note. Standard deviations are shown in brackets.

\subsection{Structural Relations}

In our initial data screening, we note that the data was normally distributed with kurtosis and skewness values for the variables falling within the $+/-2.00$ (Byrne, 1998). SEM procedures stipulate, in particular, the forming of aggregate scores to represent multiple measured indicators for each latent factor (Byrne, 1998; Marsh \& Yeung, 1997). For each latent factor, for example, there is a requirement of more than one measured indicator. The use of aggregated scores, recommended and used in previous motivational and social sciences research (e.g., Lent, Lopez, Brown, \& Gore, 1996; Marsh \& Yeung, 1997; Vispoel, 1995), is advantageous as these are more reliable and valid, decrease the effects of idiosyncrasies associated with individualized items, and reduce the computer resources required for complex analyses (Marsh \& Yeung, 1997). On this basis, similar for our subsequent analyses, we used the procedures recommended by Marsh and Yeung (1997) to form our parcel items. There are, in total, three latent factors (academic disengagement, belonging, and personal self-efficacy) and nine parcel items, with each latent factor defined by three items. Furthermore, we treated both prior learning experience and achievement in mathematics as measured variables. Overall then, there are 11 measured indicators used in the subsequent structural equation analyses.

Since the direct and indirect effects of prior learning experience on the other variables are central to the study, we 
first controlled for the possible effects from prior learning experience. In the initial structural model, Model M0, we controlled four structural paths: prior learning experience to personal self-efficacy, prior learning experience to a sense of belonging, prior learning experience to academic disengagement, and prior learning to achievement. The goodness-of-fit index values indicated a modest model fit $-\chi^{2}=283.26, \mathrm{~d} f=41, \mathrm{NNFI}=.854, \mathrm{CFI}=.891$, and RMSEA $=.143$. Model M1, an extension of the initial model, involving the controlling of paths from personal self-efficacy to a sense of belonging, academic disengagement, and achievement. For Model M2, we controlled all structural paths with the exception of freeing of a structural path from academic disengagement to achievement. Both Model M1 and Model 2 showed poor model fit, as reflected by the goodness-of-fit index values (e.g., NNFI and CFI $<.50$ ). In our hypothesized a priori model, Model, Model M3, we freed the structural paths that were controlled previously and the goodness-of-fit index values revealed a good model fit (e.g., NNFI $=.954, \mathrm{CFI}=.969$, RMSEA $=.080$ ). A summary of the goodness-of-fit index values for the four models tested is presented in Table 2.

We performed a chi-square difference test between the four models to determine which of the four models provided the best fit to the data. A chi-square difference test between Model M1 and Model M2 showed a statistically significant difference $-\Delta \chi^{2}(\mathrm{M} 2-\mathrm{M} 1)[2, N=290]=338.16, p<.001$, providing support for Model M1. Likewise, a chi-square difference test between Model M1 and Model M0 yielded a statistical significance at $p$ $<.001\left(\Delta \chi^{2}\right.$ (M1- M0) $\left.[3, N=290]=884.33, p<.001\right)$, supporting the former model. The freeing of structural paths between the variables improved the model fit from Model M0 to Model M3, and this is also reflected by the chi-square difference test $\left(\Delta \chi^{2}\right.$ (м3- м0) $\left.[4, N=290]=177.37, p<.001\right)$. In total, based on the chi-square difference tests and a comparison of the goodness-of-fit index values, there is empirical support for the acceptance of Model M3. The final solution for Model M3 is illustrated in Figure 2. For clarity, we have omitted the non-statistical significant paths. All standardized paths are significant at the $p<.01$ and $p<.001$. For the measurement aspect of the results, it is noted that each latent factor is well defined by the measured indicators, with factor loadings ranged from .88 to $.94(M n=.91, S D=.031)$ for personal self-efficacy, .37 to $.91(M n=.73$, $S D=.31)$ for belonging, and .70 to $.87(M n=.80, S D=.091)$ for disengagement.

\subsection{Direct and Indirect Effects}

In addition to Figure 2, a decomposition in direct and indirect effects is shown in Table 3. In total, there are five statistical significant structural paths. Prior learning experience exerts positive effects on personal self-efficacy $(\beta=.75, p<.001)$ and achievement in mathematics $(\beta=.22, p<.01)$. Achievement in mathematics is also influenced by both belonging $(\beta=.55, p<.001)$ and personal self-efficacy $(\beta=-.29, p<.001)$. Finally, a negative relation is established between belonging and academic disengagement $(\beta=-.23, p<.001)$. In terms of indirect effects, from Table 3, only prior learning experience influenced academic achievement via personal self-efficacy. This finding is consistent with those established in previous studies (e.g., Liem, et al., 2008; Pajares \& Kranzler, 1995; Phan, 2010), highlighting the central role that personal self-efficacy plays in mediating effects between variables.

Table 2. Goodness-of-fit index values

\begin{tabular}{|c|c|c|c|c|c|}
\hline Description & $\chi^{2}$ & $\mathrm{~d} f$ & NNFI & CFI & RMSEA \\
\hline Model MO & 283.26 & 41 & .854 & .891 & .143 \\
\hline $\begin{array}{l}\text { Paths from Prior learning to the } \\
\text { following variables controlled: } \\
\text { - Personal self-efficacy } \\
\text { - Belonging } \\
\text { - } \quad \text { Academic disengagement } \\
\text { - } \quad \text { Achievement }\end{array}$ & & & & & \\
\hline Model M1 & 1167.59 & 44 & .370 & .496 & .297 \\
\hline $\begin{array}{l}\text { Model M0 with paths from Personal } \\
\text { self-efficacy to the following variables } \\
\text { controlled: } \\
\text { - Belonging }\end{array}$ & & & & & \\
\hline
\end{tabular}


- Academic disengagement

- Achievement

Model M2

Model M1 with paths from Belonging to the following variables controlled:

- Academic disengagement

- Achievement

Model M3

Model M0 with the freeing of paths from

Prior learning to the following variables:

- Personal self-efficacy

- Belonging

- Academic disengagement

- Achievement
$1505.75 \quad 46$

.216

.344

$105.89 \quad 37$

.954

.969

.080

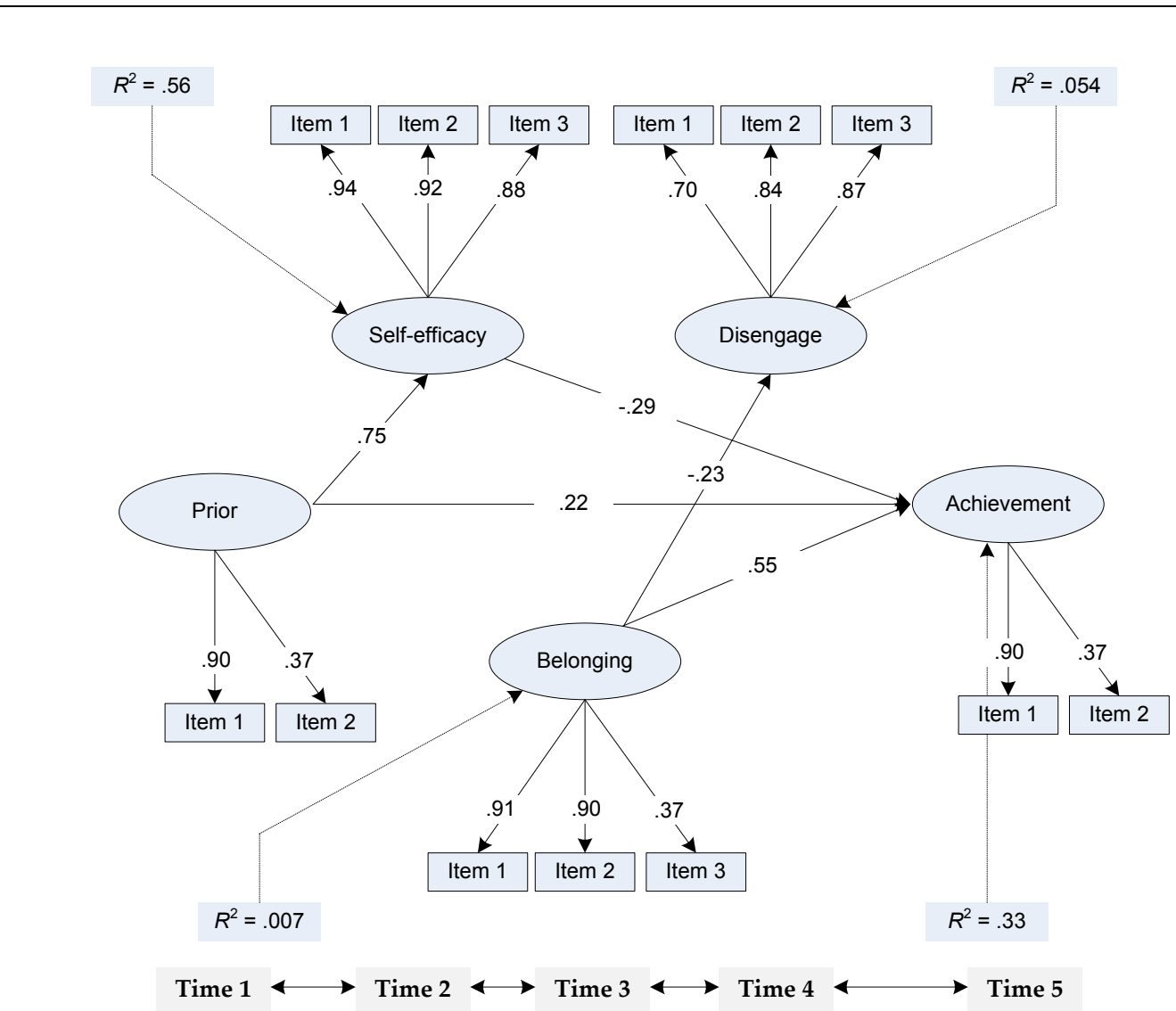

Figure 2. Final model of personal self-efficacy, belonging, and academic disengagement

Note. For clarity, non-statistical significant paths have been omitted. All paths are significant at $p<.01$ and $p$ $<.001$. 
Table 3. Decomposition of Effects: Direct, Indirect, and Total

\begin{tabular}{|c|c|c|c|c|c|c|c|}
\hline Predictor & Outcome & Direct & & Indirect & & Total & \\
\hline Prior learning & Self-efficacy & .75 & $* * *$ & .00 & & .75 & $* * *$ \\
\hline Self-efficacy & Belonging & .07 & & .00 & & .07 & \\
\hline Prior learning & & .02 & & .05 & & .07 & \\
\hline Belonging & Disengagement & -.23 & $* * *$ & .00 & & -.23 & $* * *$ \\
\hline Self-efficacy & & -.05 & & -.015 & & -.06 & \\
\hline Prior learning & & .06 & & -.05 & & .01 & \\
\hline Disengagement & Achievement & .01 & & .00 & & .01 & \\
\hline Belonging & & .55 & $* * *$ & -.002 & & .55 & $* * *$ \\
\hline Self-efficacy & & -.29 & $* * *$ & .04 & & -.25 & $* * *$ \\
\hline Prior learning & & .22 & ** & -.18 & * & .04 & $* *$ \\
\hline
\end{tabular}

Note. ${ }^{* *} p<.01, * * * p<.001$

\section{Discussion of Results}

The present research investigation focused on the study of enhancement of students' learning in achievement contexts. From an educational psychology perspective, as we emphasized previously, there are a number of theoretical orientations that have relevance in their explanatory and predictive powers. Notably, as established from the empirical literature, there are two major tenets that have important currencies for consideration: personal self-efficacy and belonging. Personal self-efficacy, as attested, is a potent indicator of performance and achievement-related outcomes (Bandura, 1997; Pajares, 1996b; Schunk, 1995). The concept of belonging, similarly, is well established and has wide range implications for educators and researchers, alike. A sense of belonging, for example, may enable individuals to feel more motivated, interested, and engaged in their social interactions and learning. Consequently, on this basis, for this study, we amalgamated different strands of inquires and proposed a conceptual model for statistical testing. Significantly, from a theoretical point of view, our interest pertains in particular to the possible triarchic associations between personal self-efficacy, belonging, and academic disengagement. The findings that we have obtained support, in part, the hypotheses that were outlined previously.

\subsection{Triarchic Relations between Personal Self-Efficacy, Belonging, and Disengagement}

The significance of our proposition detailed, in particular, the triarchic associations between personal self-efficacy, belonging, and academic disengagement. Of the three associations, we note only a statistical significant association between a sense of belonging and academic disengagement. The negative effect established is expected, whereby a sense of belonging is associated with an inclination for students to feel proactive and engaged in their schoolwork. A lack of belonging, in contrast, is more likely to disengage students from school, in general. The scope of belonging is rather complex, but entails some of the following attributes for example, the importance of acceptance, support and respect for personal autonomy, and positive values encouraged by others (Goodenow, 1993a, 1993b). The fostering of a social milieu that nurtures a sense of identification (e.g., "I feel really connected with this school; there is a sense of identity and we are all made to feel related") (Finn, 1989) is an important feat for accomplishment, as this would facilitate positive educational processes and schooling outcomes (Ma, 2003). One positive outcome of belonging, in this instance, is the promotion of students' academic engagement in their schoolwork (Becker \& Luthar, 2002; Garcia-Reid, et al., 2005; Goodenow, 1992).

As our findings indicate, a sense of belonging is proactive towards both engagement and achievements in learning (Anderman, 2002; Deci \& Ryan, 1991; Finn, 1989; Osterman, 2000; Willms, 2003). A sense of belonging, consistent with previous research studies (Gonzalez \& Padilla, 1997; Goodenow, 1993a; Ma, 2003; Osterman, 2000), is predictive of effort expenditure, motivation, and academic performance outcomes. In terms of academic learning, a culture of acceptance, tolerance, appreciation, and respect for others is conducive to excelled performance outcomes. Students who feel 'belonged', in this analysis, are more likely to demonstrate academic competence than those who experience feelings of isolation, peer rejection, etc. This negativity, of course, then results in other maladaptive outcomes and practices. 
As educators, for consideration, it is important to recognize the implications that arise from an absence in school belonging. Implicit manifestation of oblivion, cultural ignorance, and inactions in school, for example, may leave some students feeling disenfranchised and lost. Consequently, on this basis, with a sense of disconnection and stigmatization, some students may drop out from school altogether (Anderman, 2002; Fine, 1991; Finn, 1989) and partake in antisocial activities, etc. (Ma, 2003). Limited in our current examination, other researchers could advance and explore further the consequences of the belonging-disengagement relationship. The work of Henry and her colleagues (Henry, 2010; Henry, et al., 2012), in particular, has been prominent, involving a study of detrimental consequences such as student dropout and delinquency that arise from academic disengagement.

Personal self-efficacy, in this case, was ineffective as an antecedent of belonging and academic disengagement. What is of statistical significance, and consistent with existing research studies (e.g., Pajares, 1996b; Pajares \& Kranzler, 1995; Pajares \& Miller, 1994; Phan, 2013; Schunk, 1995; William \& Williams, 2010), is the relation between self-efficacy and academic achievement. What is different, however, is the magnitude in the predictive effect of personal self-efficacy, whereby a heightened sense is less likely to enhance students' learning in achievement contexts. This finding is somewhat perplexing and we query the extent to which the issue of alignment (Bandura, 1997; Pajares, 1996b) might have explained this mixed finding. This premise from our point of view has merits, especially given that there were non-statistical significant effects of personal self-efficacy on both belonging and academic disengagement. The tenets of self-efficacy (Bandura, 1997) indicate that self-efficacy, as a theoretical construct, is more explanatory and predictive when it (e.g., "How confident that you have the capability to solve this mathematics problem: solve for $x, x^{2}+2 \mathrm{x}=-16$ ?") aligns closely to the criterial tasks at hand (e.g., "Solve for $y, y^{3}+2 y^{2}-y=0$ "). When misalignment results, as often the case when researchers use indexes of performance and achievement-related outcomes that have very little, if any, relatedness to the self-efficacy items at hand. The issue then, in this analysis, is whether a refinement in the construction of the self-efficacy items could have made a difference? One limitation of our study, which we mentioned previously, is that we used the students' end-of-term results as indexes of mathematics achievement. Ideally, if time had been available, we would have preferred to use an in-class test with items aligning to the self-efficacy criteria.

Another emphasis that has been noted in the self-efficacy literature is one's own calibration of self-efficacy beliefs in educational settings (Bandura, 1997; Pajares, 1996b). Calibration, according to Pajares (1996), entails the extent to which one is accurate in his/her judgment of competence. Pajares and his colleagues have studied calibration of self-efficacy beliefs for academic learning (e.g., Pajares, 1996a; Pajares \& Kranzler, 1995; Pajares \& Miller, 1994), and evidence arising from this line of inquiry indicates some significance for applied teaching practices. Were our students serious in their judgments and reporting of self-efficacy beliefs? We need to consider, for example, the potential problems of being overconfident and whether this inaccuracy could deter students' learning and performance outcomes. How much confidence is enough confidence before it becomes harmful, psychologically, for students? The same positioning also applies to the notion of underconfidence, whereby this state of personal self-efficacy may create a sense of indecision and uncertainty. The Importance Prior Learning Experience

Prior learning experience has been recognized by Bandura (1997) to make a major contribution in the formation of personal self-efficacy. Researchers (e.g., Liem, et al., 2008; Matsui, Matsui, \& Ohnishi, 1990; Phan, 2012a) using students' prior academic grades havereported findings that emphasize the predictive effect of enactive learning experiences academic self-efficacy beliefs. Evidence ascertained from our structural equation analyses, similarly, provides consistent empirical support for the role of prior learning experiences, as an antecedent of personal self-efficacy. This collective evidence emphasizes the potency of personal learning experiences, subject to both mastery criteria and performance-based initiatives (e.g., achieving for social recognition). Repeated and ongoing successes in mathematics learning, say, are more likely to enhance students' beliefs about their capabilities. Continuing failures, in contrast, weaken one's sense of personal self-efficacy and its related outcomes. This finding, of course, may provide educators with considerations of other possible sources that could enhance self-efficacy beliefs for academic learning. Bandura's (1997) theoretical tenets suggest that, perhaps, other antecedents may be more informative. Previous research studies have shown, for example, that informational sources such as vicarious experiences (Hampton, 1998; Lopez \& Lent, 1992; Matsui, et al., 1990; Phan, 2012a), verbal persuasion (Pajares, et al., 2007; Phan, 2012b), and emotional states (Lopez \& Lent, 1992; Pajares, et al., 2007; Phan, 2012b) make marginal contributions in the formation of personal self-efficacy. Consequently, on this basis, one could resort to non-learning and non-performance sources to assist in the cognitive appraisal of capability. Vicariously, for instance, exposure to appropriate role models and the sequenced steps involved in observation, imitation, and action could serve in place of enactive learning 


\section{experience.}

What is interesting, though, is that the hypothesized effects of prior learning experiences on belonging and academic disengagement were not supported from our structural equation analyses. Similarly, as we mentioned previously, the impact of personal self-efficacy on these two theoretical constructs was non-statistical significant. We have also established, in this instance, that belonging relates closely to academic disengagement. We query whether these two constructs could, perhaps, feature in a larger sociocultural system of change that involves other contributing factors. Non-individualistic attributes, such as a community or a school's own policy on pastoral care may instead affect students' sense of belonging and academic disengagement. Extracurricular and/or non-scholastic activities, for example, are non-competitive and non-threatening and may, in contrast, stimulate positive student perceptions of unity, respect, and cultural acceptance. A school social milieu that emphasizes academic excellence and competitions for success may, likewise, alienate some students from schoolwork, especially those who are less able. It would be of considerable interest, then, for researchers to explore and identify other extraneous sources and/or internal cognitive processes that could act in tandem to influence students' sense of belonging and their state of academic engagement/disengagement.

From an educational perspective, the key findings established in this investigation provide grounding for consideration into applied practices. The importance of school belonging, for example, indicates that apart from school, the community and family may also play a major role. The question for consideration, in this analysis, entails the strategies and approaches that a family may provide to enhance a sense of belonging. Appropriate parenting and parental involvement (Chow \& Chu, 2007; Okagaki \& Frensch, 1998), in this analysis, may serve as basis for students to identify with others and establish a social connectedness. A home climate with the availability of resources or whereby parents take part in their children's learning (e.g., spending three hours per day)(Hood, Conlon, \& Andrews, 2008; LeFevre, Polyzoi, Skwarchuk, Fast, \& Sowinski, 2010; Rashid, Morris, $\&$ Sevcik, 2005) may create and stimulate a sense of positive emotions. This enriched and welcoming home milieu may, in turn, translate to feelings of serenity, appreciation, and acceptance towards others in a school context.

Sociocultural tenets (Bronfenbrenner, 1989; Okagaki, 2001; Phan, 2012c; Phan, Maebuta, \& Dorovolomo, 2010), detailed from the empirical literature, suggest the potency and impact of social and cultural attributes from society, in general. A community, for that matter, may involve and contribute to the enhancement of students' self-esteem, self-efficacy beliefs, and confidence. Communalism, for example, may foster a moral compass that embraces cultural acceptance, diversity, and inclusiveness, thereby instilling a sense of commitment, belonging, and group identity. A collective society, subsequently, may translate and cultivate a sense of school and community belonging, binding individuals and families together. We suggest future research investigations consider this avenue of inquiry, and explore the psychosocial influences from families and the community on students' academic engagement and sense of belonging.

\subsection{Directions for Future Research}

Findings ascertained from this investigation provide, in our view, grounding for continuing research development. Methodologically, for example, the use of a cross-sectional design in the current study is limited in theoretical inference, and does not allow us to consider other patterns in findings. Our staggered multiple time points in data collection were not designed or stipulated as a true longitudinal study, and as such, this limited us, methodologically. One avenue of inquiry for consideration, in particular, involves the study of causal effects and reciprocal relationships. One distinctive emphasis that we made concerns the triarchic relations between personal self-efficacy, belonging, and academic disengagement. From an alternative perspective in theorization, we query whether academic disengagement could, in fact, impact on a sense belonging. Some students may disengage from their community and school, as a result of poor achievements (Bloom, 1976) and/or a perception that they are in untenable peer relationships. This state of disengagement may, consequently, result in a perception of isolation, unacceptance, and students choosing to withdraw themselves from society, in general. A state of disengagement may, similarly, weaken one's own self-efficacy towards academic learning and proactive achievement-related behaviours. Longitudinal data analysed within the framework of SEM (Byrne, 1998; Loehlin, 2004), in contrast, provide a stronger premise for validation in the issue of causal predominance (Marsh \& Yeung, 1997, 1998).

Apart from causal predominance perspective (Marsh \& Yeung, 1997, 1998), one statistical advance for consideration entails the statistical testing for individual differences. A post hoc analysis in our examination, which we did not report because of its statistical insignificance, showed no statistical significant differences between boys and girls. With larger sample sizes, and even data that are drawn from different geographical 
locations (e.g., rural school versus metropolitan school) and regions (e.g., Australia, Singapore), researchers could potentially explore individual differences between groups (e.g., boy $\times$ girl) via means of factorial invariance (Byrne, 1998, 2010) and/or hierarchical linear modelling (Little, 2000; MacCallum, Kim, Malarkey, \& Kiecolt-Glaser, 1997; Raudenbush \& Bryk, 2001).

In a larger system of learning and change, we also need to consider other internal cognitive processes and sociocultural factors that could serve as antecedents or consequences of personal self-efficacy, belonging, and academic disengagement. From a global, educational perspective, for example, it is important to recognize the non-achievement and achievement-related outcomes that relate to one's own academic engagement. The relevance of belonging and academic engagement cannot be overstated, especially in relation to youths and ethnic minorities. The work of Henry and her colleagues (Henry, 2010; Henry, et al., 2012), as we mentioned previously, highlights the detrimental consequences of disengagement, and we could, similarly, include their work to our focus of inquiry. Importantly, from a longitudinal perspective, it would be fruitful for researchers to explore potential strategies that could alleviate feelings, perceptions, and experience of academic disengagement. Some notable possibilities, of course, may include social and pastoral care policies and extracurricular social activities that de-emphasize the importance of academic competition and social comparison. The peer-buddy mentoring system used in some secondary schools, for example, may encourage unity and acceptance of differences. This mentoring and leadership process in school may, consequently, facilitate a sense of belonging for students. This in-school care, stimulating a sense of belonging, may in turn nurture students and encourage them to participate in school activities, events, and outings without feeling threatened. Researchers could explore the long-term non-academic effects of academic engagement and disengagement, arising from school belonging, from an in situ societal perspective. How does academic engagement at school assist post-secondary school students in their democratic values and inclination towards civic citizenship? Similarly, maladaptively, to what extent does academic disengagement lead to serious criminal offences?

Likert-scale inventories, alone, cannot capture the scope and complexities of belonging and academic disengagement. Self-rating reports of Likert-scale items, for example, are limited and do not account for the ever changing, continuous experiences and feelings of students, based on their daily interactions with others. Self-judgments and reports of personal experience do not necessarily reflect the impact and contributions of sociocultural attributes (e.g., peer pressure). We could consider, alternatively, the use of in situ observations and/or teachers' own school term reports of students' learning and achievements. Peer assessment, via means of mentoring and leadership programs, may also provide information regarding students' states of emotional and social well-being.

\section{References}

Anderman, E. M. (2002). School effects on psychological outcomes during adolescence. Journal of Educational Psychology, 94(4), 795-809. http://dx.doi.org/10.1037/0022-0663.94.4.795

Bandura, A. (1977). Self-efficacy: Toward a unifying theory of behavioral change. Psychological Review, 84, 191-215. http://dx.doi.org/10.1037/0033-295X.84.2.191

Bandura, A. (1986). Social foundations of thought and action: A social cognitive theory. New Jersey: Prentice-Hall, Inc.

Bandura, A. (1997). Self-efficacy: The exercise of control. New York: W. H. Freeman \& Co.

Bandura, A. (2002). Social cognitive theory in cultural context. Applied Psychology: An International Review, 51(2), 269-290. http://dx.doi.org/10.1111/1464-0597.00092

Baumeister, R. F., \& Leary, M. R. (1995). The need to belong: Desire for interpersonal attachments as a fundamental human motivation. Psychological Bulletin, 117, 497-529. http://dx.doi.org/10.1037/0033-2909.117.3.497

Becker, B. E., \& Luthar, S. S. (2002). Social-emotional factors affecting achievement outcomes among disadvantaged students: Closing the achievement gap. Educational Psychologist, 37(4), 197-214. http://dx.doi.org/10.1207/S15326985EP3704_1

Bloom, B. (1976). Human characteristics and school learning. New York: McGraw-Hill.

Bong, M. (2001). Role of self-efficacy and task-value in predicting college students' course performance and future enrollment intentions. Contemporary Educational Psychology, 26, 553-570. http://dx.doi.org/10.1006/ceps.2000.1048

Britner, S. L., \& Pajares, F. (2006). Sources of science self-efficacy beliefs of middle school students. Journal of 
Research in Science Teaching, 43, 485-499. http://dx.doi.org/10.1002/tea.20131

Bronfenbrenner, U. (1989). Ecological systems theory In R. Vasta (Ed.), Annals of child development: Theories of child development: Revised formulations and current issues (Vol. 6, pp. 187-251). Greenwich, CT: JAI Press.

Byrne, B. M. (1998). Structural equation modelling with LISREL, PRELIS, and SIMPLIS. Mahwah, NJ: Erlbaum.

Byrne, B. M. (2010). Structural equation modeling with AMOS: Basic concepts, applications, and programming (2nd ed.). New York, NY: Routledge.

Capps, M. A. (2003). Characteristics of a sense of belonging and its relationship to academic achievement of students in selected middle schools in Region IV and VI Educational Service Centers. Doctor of Philosophy, Texas A\&M University, Texas.

Chou, C. P., \& Bentler, P. M. (1995). Estimates and tests in structural equation modelling. In R. H. Hoyle (Ed.), Structural equation modelling: Concepts, issues, and applications (pp. 37-55). Thousand Oaks, CA: Sage.

Chow, S. S.-Y., \& Chu, M. H.-T. (2007). The impact of filial piety and parental involvement on academic achievement motivation in Chinese secondary school students. Asian Journal of Counsellung, 14(1 \& 2), 91-124.

Connell, J. P., \& Wellborn, J. G. (1991). Competence, autonomy, and relatedness: A motivational analysis of self-system processes. The Minnesota Symposia on Child Development: Self-Processes and Development, 23, 43-77.

Deci, E. L., \& Ryan, R. M. (1991). A motivational approach to self: Integration in personality. In R. Dienstbier (Ed.), Nebraska symposium on motivation: Vol. 38, Perspectives on motivation (Vol. 38, pp. 237-288). Lincoln, NE: University of Nebraska Press.

Diseth, Å. (2011). Self-efficacy, goal orientations and learning strategies as mediators between preceding and subsequent academic achievement. Learning and Individual Differences, 21(2), 191-195. http://dx.doi.org/10.1016/j.lindif.2011.01.003

Fast, L. A., Lewis, J. L., Bryant, M. J., Bocian, K. A., Cardullo, R. A., Rettig, M., et al. (2010). Does math self-efficacy mediate the effect of perceived classroom environment on standardized math performance? Journal of Educational Psychology, 102(3), 729-740. http://dx.doi.org/10.1037/a0018863

Fenollar, P., Román, S., \& Cuestas, P. J. (2007). University students' academic performance: An integrative conceptual framework and empirical analysis. British Journal of Educational Psychology, 77, 873-891. http://dx.doi.org/10.1348/000709907X189118

Fine, M. (1991). Framing dropouts. Albany, NY: SUN Press.

Finn, J. (1989). Withdrawing from school. Review of Educational Research, 59, 117-142. http://dx.doi.org/10.3102/00346543059002117

Fredricks, J. A., Blumenfeld, P. C., \& Paris, A. H. (2004). School engagement: Potential of the concept, state of the evidence. Review of Educational Research, 74, 59-109. http://dx.doi.org/10.3102/00346543074001059

Furrer, C., \& Skinner, E. (2003). Sense of relatedness as a factor in children's academic engagement and $\begin{array}{lllll}\text { performance. Journal of Educational Psychology, } & \text { 95(1), }\end{array}$ http://dx.doi.org/10.1037/0022-0663.95.1.148

Garcia-Reid, P., Reid, R. J., \& Peterson, N. A. (2005). School engagement among Latino youth in urban middle school context: Valuing the role of social support. Education and Urban Society, 37, 257-275. http://dx.doi.org/10.1177/0013124505275534

Gonzalez, R., \& Padilla, A. M. (1997). The academic resilience of Mexican American high school students. Hispanic Journal of Behavioral Sciences, 19, 301-317. http://dx.doi.org/10.1177/07399863970193004

Goodenow, C. (1992). Strengthening the links between educational psychology and the study of social contexts. Educational Psychologist, 27(2), 177-196. http://dx.doi.org/10.1207/s15326985ep2702_4

Goodenow, C. (1993a). Classroom belonging among early adolescent students: Relationships to motivation and achievement. Journal of Early Adolescence, 13(1), 21-43. http://dx.doi.org/10.1177/0272431693013001002

Goodenow, C. (1993b). The psychological sense of school membership among adolescents: Scale development and educational correlates. Psychology in the Schools, 30, 79-90. 
http://dx.doi.org/10.1002/1520-6807(199301)30:1<79::AID-PITS2310300113>3.0.CO;2-X

Goodenow, C., \& Grady, K. (1993). The relationship of school belonging and friends' values to academic motivation among urban adolescent students. The Journal of Experimental Education, 60, 60-71. http://dx.doi.org/10.1080/00220973.1993.9943831

Greene, B. A., \& Miller, R. B. (1996). Influences on achievement: Goals, perceived ability, cognitive $\begin{array}{lllll}\text { engagement. Contemporary } & \text { Educational 181-192. }\end{array}$ http://dx.doi.org/10.1006/ceps.1996.0015

Greenwood, C. R., Horton, B. T., \& Utley, C. A. (2002). Academic engagement: Current perspectives in research and practice. School Psychology Review, 31(3), 1-31.

Hampton, N. Z. (1998). Sources of academic self-efficacy scale: An assessment tool for rehabitation counselors. Rehabilitation Counseling Bulletin, 41(4), 374-389.

Henry, K. L. (2010). Academic achievement and adolescent drug use: An examination of reciprocal effects and correlated growth trajectories. Journal of School Health, 80(1), 38-43. http://dx.doi.org/10.1111/j.1746-1561.2009.00455.x

Henry, K. L., Knight, K. E., \& Thornberry, T. P. (2012). School disengagement as a predictor of dropout, delinquency, and problem substance use during adolescence and early adulthood. Journal of Youth Adolescence, 41, 156-166. http://dx.doi.org/10.1007/s10964-011-9665-3

Hood, M., Conlon, E., \& Andrews, G. (2008). Preschool home literacy practices and children's literacy development: A longitudinal analysis. Journal of Educational Psychology, 100(2), 252-271. http://dx.doi.org/10.1037/0022-0663.100.2.252

Jöreskog, K. G., \& Sörbom, D. (2001). LISREL 8: User's reference guide [software manual]. Chicago: Scientific Software.

Kline, R. B. (2011). Principles and practice of structural equation modeling (3rd ed.). New York, NY: The Guilford Press.

LeFevre, J.-L., Polyzoi, E., Skwarchuk, S.-L., Fast, L., \& Sowinski, C. (2010). Do home numeracy and literacy practices of Greek and Canadian parents predict the numeracy skills of kindergarten children? International Journal of Early Years Education, 18(1), 55-70. http://dx.doi.org/10.1080/09669761003693926

Lent, R. W., Lopez, F. G., \& Bieschke, K. J. (1991). Mathematics self-efficacy: Sources and relation to science-based career choice. Journal of Counseling Psychology, 38, 424-430. http://dx.doi.org/10.1037/0022-0167.38.4.424

Lent, R. W., Lopez, F. G., Brown, S. D., \& Gore, P. A. (1996). Latent structure of the sources of mathematics self-efficacy. Journal of Vocational Behavior, 49, 292-308. http://dx.doi.org/10.1006/jvbe.1996.0045

Liem, A. D., Lau, S., \& Nie, Y. (2008). The role of self-efficacy, task value, and achievement goals in predicting learning strategies, task disengagement, peer relationship, and achievement outcome. Contemporary Educational Psychology, 33, 486-512. http://dx.doi.org/10.1016/j.cedpsych.2007.08.001

Little, T. D. (2000). Modeling longitudinal and multilevel data: Practical issues, applied approaches, and specific examples. Mahwah, NJ: Lawrence Erlbaum.

Loehlin, J. C. (2004). Latent variable models: An introduction to factor, path, and structural equation analysis (4th ed.). Mahwah, NJ: Lawrence Erlbaum Associates, Publishers.

Lopez, F. G., \& Lent, R. (1992). Sources of mathematics self-efficacy in high school students. Career Development Quarterly, 41, 3-12. http://dx.doi.org/10.1002/j.2161-0045.1992.tb00350.x

Ma, X. (2003). Sense of belonging to school: Can schools make a difference? Journal of Educational Research, 96(6), 1-9. http://dx.doi.org/10.1080/00220670309596617

MacCallum, R. C., Kim, C., Malarkey, W. B., \& Kiecolt-Glaser, J. K. (1997). Studying multivariate change using multilevel models and latent curve models. Multivariate Behavioral Research, 32(3), 215-253. http://dx.doi.org/10.1207/s15327906mbr3203_1

Marsh, H. W., \& Yeung, A. S. (1997). Causal effects of academic self-concept on academic achievement: Structural equation models of longitudinal data. Journal of Educational Psychology, 89(1), 41-54. http://dx.doi.org/10.1037/0022-0663.89.1.41

Marsh, H. W., \& Yeung, A. S. (1998). Longitudinal structural equation models of academic self-concept and 
achievement: Gender differences in the development of math and English constructs. American Educational Research Journal, 35(4), 705-738. http://dx.doi.org/10.3102/00028312035004705

Martin, A. J., \& Marsh, H. (2005). Motivating boys and motivating girls: Does teacher gender really make a $\begin{array}{llll}\text { difference? Australian Journal of } & \text { 320-334. }\end{array}$ http://dx.doi.org/10.1177/000494410504900308

Matsui, T., Matsui, K., \& Ohnishi, R. (1990). Mechanisms underlying math self-efficacy learning of college students. Journal of Vocational Behavior, 37, 225-238. http://dx.doi.org/10.1016/0001-8791(90)90042-Z

Moretti, E. (2005). Does education reduce participation in criminal actitivies. In H. M. C. Levin (Ed.), Symposium on the social costs on inadequate education conducted at Teachers College. New York: Columbia University.

Murray, H. A. (1938). Explorations in personality: A clinical and experimental study of fifty men of college age. New York: Oxford University Press.

Okagaki, L. (2001). Triarchic model of minority children's school achievement. Educational Psychologist, 36(1), 9-20. http://dx.doi.org/10.1207/S15326985EP3601_2

Okagaki, L., \& Frensch, P. A. (1998). Parenting and children's school achievement: A multi-ethnic perspective. American Educational Research Journal, 35, 123-144. http://dx.doi.org/10.3102/00028312035001123

Osterman, K. F. (2000). Students' need for belonging in the school community. Review of Educational Research, 70, 323-367. http://dx.doi.org/10.3102/00346543070003323

Pajares, F. (1996a). Self-Efficacy beliefs and mathematical problem-solving of gifted students. Contemporary Educational Psychology, 21, 325-344. http://dx.doi.org/10.1006/ceps.1996.0025

Pajares, F. (1996b). Self-efficacy beliefs in academic settings. Review of Educational Research, 66(4), 543-578. http://dx.doi.org/10.3102/00346543066004543

Pajares, F., Johnson, J., J, \& Usher, E. L. (2007). Sources of writing self-efficacy beliefs of elementary, middle, and high school students. Research in the Teaching of English, 42(1), 104-120.

Pajares, F., \& Kranzler, J. (1995). Self-efficacy beliefs and general mental ability in mathematical problem solving. Contemporary Educational Psychology, 20, 426-443. http://dx.doi.org/10.1006/ceps.1995.1029

Pajares, F., \& Miller, D. (1994). Role of self-efficacy and self-concept beliefs in mathematical problem solving: A path analysis. Journal of Educational Psychology, 86, 193-203. http://dx.doi.org/10.1037/0022-0663.86.2.193

Phan, H. P. (2010). Students' academic performance and various cognitive processes of learning: An integrative framework and empirical analysis. Educational Psychology, 30(3), 297-322. http://dx.doi.org/10.1080/01443410903573297

Phan, H. P. (2011). Cognitive processes in university learning: A developmental framework using structural equation modelling. British Journal of Educational Psychology, 81(3), 509-530. http://dx.doi.org/10.1348/2044-8279.002000

Phan, H. P. (2012a). Informational sources, self-efficacy, and achievement: A temporally displaced approach. Educational Psychology, 32(6), 699-726. http://dx.doi.org/10.1080/01443410.2012.708320

Phan, H. P. (2012b). Relations between informational sources and self-efficacy: A developmental approach. Educational Psychology, 32(1), 81-105. http://dx.doi.org/10.1080/01443410.2011.625612

Phan, H. P. (2012c). A sociocultural perspective of learning: Developing a new theoretical tenet. Paper presented at the Australian Association for Research in Education, $2^{\text {nd }}-6^{\text {th }}$ December, University of Sydney, Sydney.

Phan, H. P. (2013). Interplay between cognitive and non-cognitive processes: Review, implications, and directions. In L. Zhang, \& J. Chen (Eds.), Academic achievement: Predictors, Learning Strategies and Influences of Gender (pp. 1-32). Hauppauge, NY: Science Nova Publishing.

Phan, H. P., Maebuta, J., \& Dorovolomo, J. (2010). The relations between personal epistemology and learning approaches in sociocultural contexts: A theoretical conceptualization - Part II. The International Journal of Learning, 17(5), 465-478.

Pintrich, P. R., Smith, D. A. F., Garcia, T., \& McKeachie, W. J. (1991). A manual for the use of the Motivated Strategies for Learning Questionnaire (MSLQ). Ann Arbor, MI: National Centre for Research to Improve Postsecondary Teaching and Learning. 
Prat-Sala, M., \& Redford, P. (2010). The interplay between motivation, self-efficacy, and approaches to studying. British Journal of Educational Psychology, 80(2), 283-305. http://dx.doi.org/10.1348/000709909X480563

Rashid, F. L., Morris, R. D., \& Sevcik, R. A. (2005). Relationship between Home Literacy Environment and reading achievement in children with reading disabilities. Journal of Learning Disabilities, 38(1), 2-11. http://dx.doi.org/10.1177/00222194050380010101

Raudenbush, S. W., \& Bryk, A. S. (2001). Hierarchical linear models: Applications and data analysis methods (2nd ed.). Newbury Park: Sage.

Rogers, C. R. (1951). Client-centered therapy: Its current practice, implications, and theory. Boston, MA: Houghton Mifflin.

Rouse, C. E. (2005). The labor market consequences of an inadequate education. In H. M. C. Levin (Ed.), Symposium on the social costs on inadequate education conducted at Teachers College. New York: Columbia University.

Ryan, R. M. (1993). Agency and organization: Intrinsic motivation, autonomy and the self in psychological development. In J. Jacobs (Ed.), Nebraska symposium on motivation: Developmental perspectives on motivation (Vol. 40, pp. 1-56). Lincoln, NE: University of Nebraska Press.

Schumacker, R. E., \& Lomax, R. G. (2004). A beginner's guide to structural equation modeling (2nd ed.). Mahwah, NJ: Lawrence Erlbaum Associates, Inc.

Schunk, D. H. (1995). Self-efficacy and education and instruction. In J. E. Maddux (Ed.), Self-efficacy, adaptation, and adjustment: Theory, research and application (pp. 283-301). New York: Plenum Press. http://dx.doi.org/10.1007/978-1-4419-6868-5_10

Sins, P. H. M., van Joolingen, W. R., Savelsbergh, E. R., \& van Hout-Wolters, B. (2008). Motivation and performance within a collaborative computer-based modeling task: Relations between students' achievement goal orientation, self-efficacy, cognitive processing, and achievement. Contemporary Educational Psychology, 33, 58-77. http://dx.doi.org/10.1016/j.cedpsych.2006.12.004

Usher, E. L., \& Pajares, F. (2009). Sources of self-efficacy in mathematics: A validation study. Contemporary Educational Psychology, 34, 89-101. http://dx.doi.org/10.1016/j.cedpsych.2008.09.002

Vallerand, R. J. (1997). Towards a hierarchical model of intrinsic and extrinsic motivation. In M. P. Zanna (Ed.), Advances in experimental social psychology (pp. 271-360). New York: Academic Press.

Vispoel, W. P. (1995). Self-concept in the arts: An extension of the Shavelson model. Journal of educational Psychology, 87, 134-145. http://dx.doi.org/10.1037/0022-0663.87.1.134

Voelkl, K. (1997). Identification with school. American Journal of Education, 105, 294-318. http://dx.doi.org/10.1086/444158

William, T., \& Williams, K. (2010). Self-efficacy and performance in mathematics: Reciprocal determinism in 33 nations. Journal of educational Psychology, 102(2), 453-466. http://dx.doi.org/10.1037/a0017271

Willms, J. D. (2003). Student engagement at school: A sense of belonging and participation. Results from PISA 2000: Organisation for Economic Co-operation and Development (OECD).

Wolters, C. A. (2003). Understanding procrastination from a self-regulated perspective. Journal of Educational Psychology, 95, 179-187. http://dx.doi.org/10.1037/0022-0663.95.1.179

Wong, N.-Y., \& Watkins, D. (1998). A longitudinal study of the psychosocial environmental and learning approaches in the Hong Kong classroom. The Journal of Educational Research, 91(4), 247-254. http://dx.doi.org/10.1080/00220679809597550

Woolf, S. H., Johnson, R. E., Phillips, R. L., \& Philipsen, M. (2007). Giving everyone the health of the educated: An examination of whether social change would save more lives than medical advances. American Journal of Public Health, 97, 679-683. http://dx.doi.org/10.2105/AJPH.2005.084848

\section{Copyrights}

Copyright for this article is retained by the author(s), with first publication rights granted to the journal.

This is an open-access article distributed under the terms and conditions of the Creative Commons Attribution license (http://creativecommons.org/licenses/by/3.0/). 